\title{
IRIS VARIX
}

\author{
LEONARD PEK KIANG ANG ${ }^{1}$, DANIEL HAN JEN SIM ${ }^{1}$, GILBERT SHIH CHUIN CHIANG \\ and VICTOR SHEE HEUNG YONG ${ }^{1}$ \\ Singapore
}

\begin{abstract}
SUMMARY
Varix of the iris as a solitary primary lesion is rare. We report a 31-year-old Indian man with an iris varix who developed recurrent haemorrhages into the anterior chamber which led to secondary glaucoma. An iridectomy was performed and the diagnosis was confirmed histologically. There has been no recurrence of the lesion 3 years after surgery.
\end{abstract}

Varix of the iris is extremely rare. The first reported case was by Anderson and Other. ${ }^{1}$ The diagnosis of iris varix may be difficult to establish without histological confirmation as other lesions may appear similar and also present with haemorrhage into the anterior chamber and secondary glaucoma. These lesions include iris haemangioma, malignant melanoma, juvenile xanthogranuloma, metastasis and fibrovascular proliferative response following inflammation or haemorrhage. We are reporting this single case of iris varix because of its rarity, the diagnostic confusion it may give rise to and the options in treatment.

\section{CASE REPORT}

A 31-year-old Indian man first presented in December 1992 with discomfort in his right eye. He also gave a history of intermittent blurring of vision for which he had not previously sought medical attention. There was no history of ocular trauma.

Examination showed no evidence of any previous trauma in either eye. Visual acuity was $6 / 6$ in both eyes. The left eye was normal. In the right eye, a microscopic hyphaema was noted in the anterior chamber but without any significant inflammation. A multiloculated vascular lesion was seen in the central third of the iris between the 4 and 6 o'clock positions

From: ${ }^{1}$ Department of Ophthalmology, Tan Tock Seng Hospital, Singapore; ${ }^{2}$ Department of Pathology, Singapore General Hospital, Singapore.

Correspondence to: Dr Daniel Han Jen Sim, Department of Ophthalmology, Tan Tock Seng Hospital, Moulmein Road, Singapore 308433.

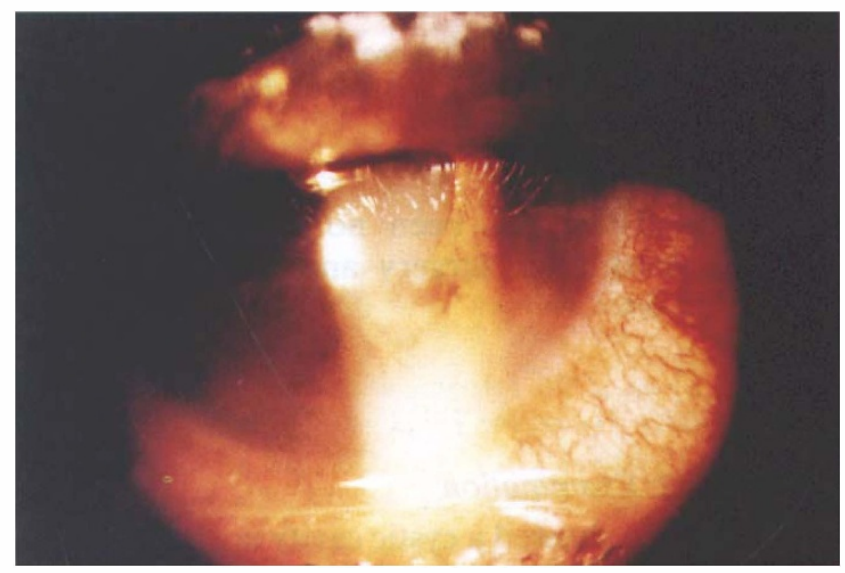

Fig. 1. Iris varix at the time of presentation.

(Fig. 1). The lesion consisted of dilated translucent vacuoles from which blood appeared to be leaking into the anterior chamber in some places. The lesion measured $1.4 \mathrm{~mm} \times 1.6 \mathrm{~mm}$ in size with surrounding normal iris architecture. The pupil was round and reactive. The intraocular pressure was $14 \mathrm{mmHg}$ in each eye by Goldmann applanation tonometry. Both fundi were normal.

The patient was treated with topical steroids (betamethasone). Over the next few months he continued to have intermittent blurring of vision and recurrent haemorrhages from the lesion. $\mathrm{He}$ subsequently developed secondary glaucoma with an intraocular pressure of $58 \mathrm{mmHg}$ and required oral acetazolamide (Diamox) and a topical beta blocker (timolol 0.5\%).

The lesion gradually increased in size over 5 months to $1.8 \mathrm{~mm} \times 2.0 \mathrm{~mm}$ with an increase in the number of vacuoles. There was recurrent leakage of blood from the vacuoles into the anterior chamber. This led to recurrent episodes of blurring with raised pressure and the formation of a blood level in the vacuoles.

In April 1993 the patient underwent an iridectomy to remove the lesion. The post-operative course was uneventful and the patient's visual acuity was $6 / 6$ 


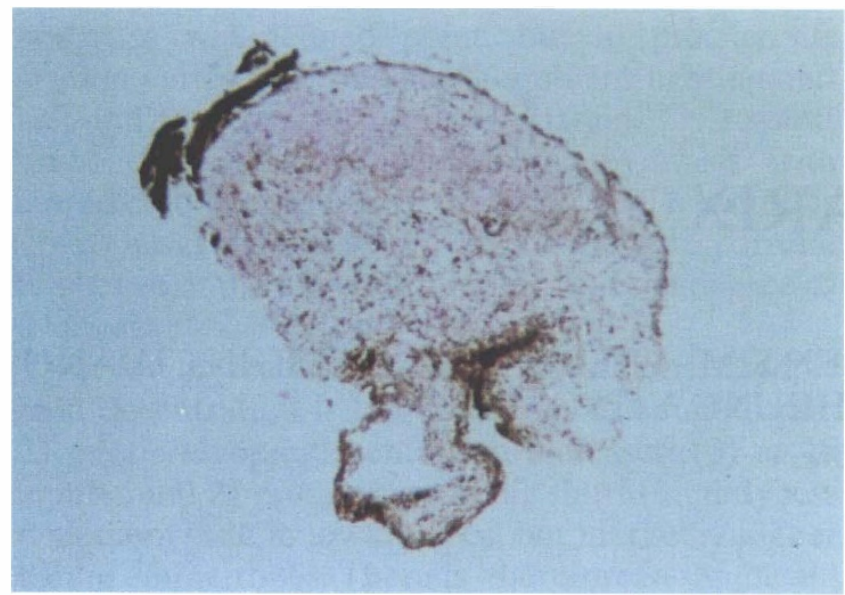

Fig. 2. Low-power photomicrograph of the excisional biopsy specimen containing iris varix. Haematoxylin and eosin, $\times 20$.

bilaterally. There has been no recurrence of the lesion 3 years after surgery and his visual acuity remains at $6 / 6$.

\section{Microscopic Examination}

Serial sections showed a cystic cavity arising from the anterior aspect of the iris and extending posteriorly to the iris pigment epithelium with a border of uninvolved iris stroma present on either side (Figs. 2,3 ). The specimen was too friable to retain any evidence of multilocularity. The wall of the cyst was lined by endothelium. Occasional macrophages could be seen. The cystic cavity contained some blood. The iris vasculature was essentially normal. There was no evidence of melanoma.

The histological appearance was consistent with that of a dilated iris vein and the diagnosis of an iris varix was confirmed.

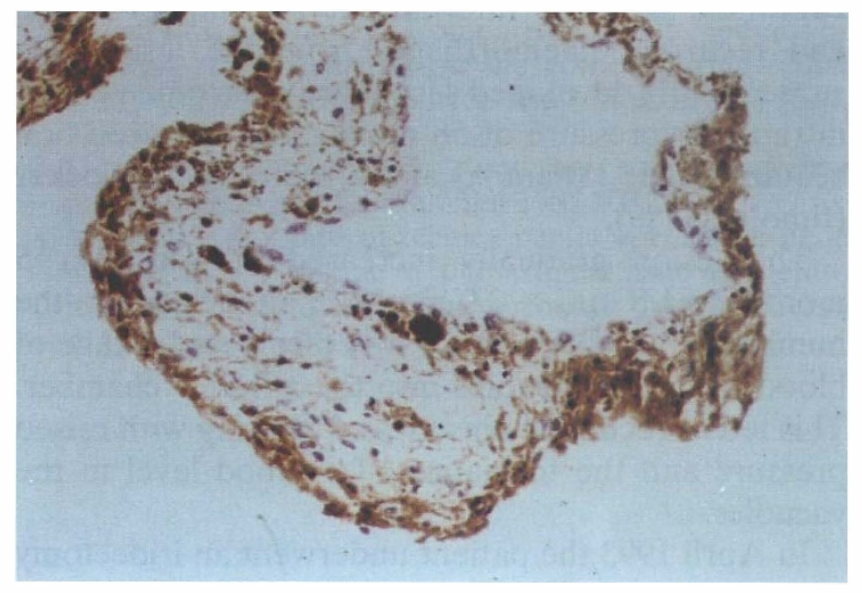

Fig. 3. High-power photomicrograph of iris varix showing an endothelium-lined vascular channel. Haematoxylin and eosin, $\times 100$.

\section{DISCUSSION}

Varices of the iris are rare. In this case of iris varix, no evidence was found to suggest that it was secondary to any other pathology. Venous obstruction or thrombosis is thought to be the cause of a varix. The first reported case of iris varix as a primary vascular lesion was by Andersen and Other in $1975 .{ }^{1}$ In 1992, Kuchle and Naumann ${ }^{2}$ described a case of iris varix resulting from alterations in the iris vessel walls in the pseudoexfoliation syndrome, which subsequently regressed spontaneously. Rohrbach et al..$^{3}$ reported a case of a primary iris varix which was excised. All these patients described had recurrent haemorrhages into the anterior chamber. The intermittent blurring of vision in our patient was due to the recurrent hyphaema.

The differential diagnoses of an iris varix include iris haemangioma, malignant melanoma, juvenile xanthogranuloma, metastasis and organised haemorrhage. All these can present as a nodule with recurrent haemorrhage into the anterior chamber and secondary glaucoma.

An important diagnosis to exclude is malignant melanoma. Neovascularisation occurring in iris melanomas may give a haemangiomatous aspect to the melanoma and simulate a haemangioma. Melanomas are found less commonly in pigmented races, as in this case. Hamburg ${ }^{4}$ demonstrated a case of an iris melanoma with vascular proliferation simulating a haemangioma. Baghdassarian and Spencer ${ }^{5}$ reported on an association between pseudoangioma and melanoma of the iris.

Haemangiomas vary from the capillary to the cavernous type. Ashton ${ }^{6}$ reported 3 cases $(2 \%)$ of iris haemangiomas out of 145 cases of iris tumours. Naidoff et al $^{7}$ described the clinical and histopathological features of a cavernous haemangioma seen in the iris of an infant with diffuse congenital haemangiomatosis.

Juvenile xanthogranuloma typically affects infants and children, although occasional cases have been reported in adults. ${ }^{8}$ It is a benign, self-limiting disease characterised by infiltrates of chronic inflammatory cells involving most commonly the skin and the eye. The iris is the most common part of the uvea affected.

The treatment of an iris varix is by excision or photocoagulation. Excision of the lesion by iridectomy, apart from being therapeutic, also provides a means of establishing the diagnosis, particularly when this is in doubt. A possible alternative treatment modality is the use of argon laser photocoagulation. This is possible if the point of bleeding is accessible to the laser and the diagnosis is not in doubt. Photocoagulation of the varix can cause regression. In our case, we were unable to attempt laser photocoagulation as the bleeding point was obscured by the blood-filled varicosities. 
We thank Dr William H. Spencer for his confirmation of the histological diagnosis.

Key words: Iris, Varix, Glaucoma.

\section{REFERENCES}

1. Anderson SR, Other A. Varix of the iris. Arch Ophthalmol 1975;93:32-3.

2. Kuchle M, Naumann GO. Varix node of the iris with spontaneous regression. Klin Monatsbl Augenheilkd 1992;200:233-6.

3. Rohrbach JM, Eckstein A, Schuster I. Varicose vein of the iris. Klin Monatsbl Augenheilkd 1995;207:206-7.
4. Hamburg A. Iris melanoma with vascular proliferation simulating a haemangioma. Arch Ophthalmol 1967; 82:72-6.

5. Baghdassarian SA, Spencer WH. Pseudoangioma of the iris: its association with melanoma. Report of a case. Arch Ophthalmol 1969;82:69-71.

6. Ashton N. Primary tumors of the iris. Br J Ophthalmol 1964;48:650-68.

7. Naidoff MA, Kenyon JR, Green WR. Iris haemangioma and abnormal vasculature in a case of diffuse congenital haemangiomatosis. Am J Ophthalmol 1971;72:633-44.

8. Smith MR, Sanders TW, Bresnick GH. Juvenile xanthogranuloma of the ciliary body in an adult. Arch Ophthalmol 1969;81:813-4. 